\title{
LINGÜÍSTICA COMO PADRÃO DE ESCRITA MISSIONÁRIA
}

\author{
Maria Cândida Drumond Mendes Barros
}

\begin{abstract}
This paper presents the history of two models of orthography for unwritten languages created by evangelical missions, using linguistic concepts. Their diffusion will be analysed as well as the linguistic concepts adopted for the notion of letter and the alliances established between scholars and missionaries in the formulation of these models.
\end{abstract}

\section{Introdução}

Desde o século XIX, a Lingüística tem exercido, entre as missões, o papel de modelo para criação de um estilo literário onde não há uma tradição literária. O estabelecimento de noções como letra, palavra e sentença, numa língua sem tradição de escrita, é imprescindível no processo de evangelização, já que a tradução bíblica para línguas ágrafas requer o suporte dessas noções gráficas.

O objetivo do trabalho será traçar uma história de alguns modelos de ortografia para línguas ágrafas, formulados por missões evangélicas, a partir de conceitos e princípios da Lingüística. A atenção recairá em duas obras. Uma delas é o livro Standard alphabet for reducing unwritten languages andforeign graphic systems to a uniform orthography in European Letters, de C. R. Lepsius (1863), recomendado por uma série de missões no século XIX. Seu lema ortográfico era "uma letra para cada som" e seu alfabeto estava definido em termos articulatórios.

A outra obra é o artigo Practical suggestions toward a common orthography for Indian languages of México for education ofthe natives within their own tongues, de Kenneth Pike (1938), membro da missão Summer Institute ofLinguistics (SIL). O artigo é uma das primeiras versões do modelo ortográfico do SIL, baseado no conceito de fonema como padrão de letra ("para cada fonema, um grafema").

A história desses dois modelos de ortografia será traçada através do levantamento de informações a respeito da sua difusão no mundo missionário, das linhagens teóricas dos conceitos lingüísticos empregados como noção de 
letra, e ainda, das alianças estabelecidas entre missionários e lingüistas acadêmicos na sua formulação. Maior atenção será dada ao caso do SIL.

Esse trabalho apresenta os resultados preliminares de uma pesquisa sobre escrita missionária. Por escrita missionária, entendo os casos de ortografias para línguas ágrafas que surgiram como parte de políticas de evangelização. Nesse contexto, a escrita se torna um instrumento de mudança da cultura tradicional oral.

\section{Escrita missionária}

Os missionários são tradicionalmente os principais formuladores de primeiras escritas alfabéticas para línguas ágrafas. A diferença entre católicos e evangélicos em relação a essas escritas é quanto à extensão e à forma de sua difusão. $\mathrm{Na}$ tradição católica, esses alfabetos tiveram uma circulação limitada. Às vezes, eram de domínio restrito dos missionários, com uma função erudita de documentar a cultura e a língua dos grupos nos quais atuavam os missionários.

Já entre as missões evangélicas, a escrita teve como objetivo alcançar a alfabetização massiva das comunidades a serem convertidas, pois, nessa tradição religiosa, o acesso à Palavra de Deus está vinculado ao conhecimento da escrita. A definição do que é ser alfabetizado, nesse contexto, está ligada à possibilidade de ler a Bíblia ("literacy is the ability to read the Bible fluently and with understanding") (Gudschinsky, 1951:1). Nessa definição, está presente uma das marcas da Reforma Protestante, que foi a ênfase dada à difusão da escrita como leitura individual, em vez de seu uso como leitura pública.

O sucesso da conversão evangélica se mede pela criação de uma cultura letrada no interior de uma comunidadade oral e pela vinculação dessa escrita à Igreja. Essa linha de atuação é principalmente forte nas missões que atuam através da difusão do texto bíblico traduzido nas línguas ágrafas. Nesse contexto, a formulação de uma escrita é a infra-estrutura necessária para a difusão tipográfica do texto bíblico e a alfabetização do convertido é a condição de ser de um crente maduro.

"For universal experience has long taught that it is not sufficient for the missionaries to learn the language of the natives in order to introduce Christianity permanently into any country. Only where the word of God is read by the people themselves, and where a whole people are made susceptible of the spirit of Christianity by the distribution of the Bible and of Christian school-books, can a rapid, deep and lasting work be hoped for" (Lepsius, 1863: 26). 
O Summer Institute of Linguistics (SIL), fundado em 1936, é um exemplo de missão evangélica especializada na tradução da Bíblia para línguas sem escrita. Pelas estatísticas da missão, ela manteve programas em 744 línguas, o equivalente a uma população de 70 milhões de pessoas; em $44 \%$ desses programas, a missão foi a responsável pela formulação e difusão de uma primeira escrita alfabética (SIL, 1990).

\section{Sistema de escrita alfabético-tipográfico}

Cada sistema de escrita (ideográfico, logográfico, alfabético) representa diferente tradição cultural, correspondendo a distintos critérios de legibilidade. No caso das escritas missionárias, o sistema de escrita empregado predominantemente foi o alfabético-tipográfico.

\section{a)Alfabético}

O título da obra de C R. Lepsius (Standard alphabet for reducing unwritten languages andforeign graphic systems to a uniform orthography in European letters) aponta o vínculo da escrita missionária com o sistema alfabético, quando opta pelas letras européias no processo de criação de primeiras escritas e de substituição de sistemas de escritas não-latinas por outras filiadas a essa tradição. Para um tradutor bíblico para línguas ágrafas, a noção de letra é o ponto de partida para construir padrões de equivalências, tais como o de palavra e de sentença, necessários para avaliar a correção de um texto religioso traduzido.

Ainda quando a opção missionária é pelo uso do sistema gráfico nativo na tradução dos textos cristãos, uma escrita alfabética é formulada paralelamente, com a função instrumental de servir de critério de equivalência para uso interno das missões. Esse é o caso, por exemplo, dos jesuítas no Oriente no século XVI, responsáveis por reproduzir, numa escrita alfabética, o texto cristão difundido nos sistemas ideográfico ou silábico. Também na American Bible Society (1932, in Nida, 1947:305), entre as normas requeridas para aprovação de uma tradução bíblica para publicação, estava a de se enviar uma transliteração em escrita alfabética dos textos que não seguissem o sistema gráfico europeu.

Uma característica da escrita missionária é manter a distinção de letras maiúsculas (para início de sentença, para nome próprio) e minúsculas e o emprego do conjunto de sinais de pontuação (ponto, vírgula, dois pontos etc). O uso de letras maiúsculas para o léxico cristão é um sinal gráfico importante no processo de familiarização do discurso cristão. 
b) Tipográfico

No processo de evangelização pela tradução bíblica, o missionário se apresenta como o "homem do livro" (Nida, 1947), em defesa da superioridade da obra literária como forma de conhecimento, pela fíxidez que ela permite, versus a evanescência da oralidade. O vínculo da escrita missionária com o livro faz com que as primeiras ortografias para línguas ágrafas sejam criadas sob a égide da imprensa.

Isso levou a que as primeiras imprensas destinadas à publicação de textos em línguas ágrafas fossem, em várias partes do mundo, introduzidas pelos tradutores bíblicos missionários. Foi assim no Tahiti (Mauer, s.d.) e nas ilhas Fiji (Clammer, 1976).

O alfabeto standard de Lepsius no século XIX é um exemplo de ortografia missionária criada vinculada à produção de tipos gráficos. Sua aceitação se deu concomitante à produção de moldes tipográficos, patrocinado pela Academia Real de Berlim e postos a disposição das missões (Lepsius, 1863: 42). Algumas sociedades missionárias também prometeram recursos para que as imprensas das missões moldassem tipos gráficos nesse modelo (Lepsius, 1863: xiv).

Uma característica da escrita tipográfica é possuir uma regularidade automática, diferentemente da escrita manuscrita (cartas, anotações pessoais) que se apresenta imersa em diferenças individuais (Harris, 1980: 7). Essa homogeneidade inerente à escrita tipográfica a levaria a ter maiores exigências de normatização (por exemplo, em relação às variações dialetais), diferentemente da escrita que se difunde apenas como manuscrita. A escrita tipográfica estabelece, assim, um processo prescritivo através dos mecanismos de estandardização (ou "normatização"), que determina a forma correta de escrever. A escrita de uma língua que existe apenas como manuscrita não possui instrumentos de homogenização.

O fato de escritas missionárias terem sido criadas sob os parâmetros tipográficos fez com que escritas em línguas ágrafas tenham uma história diferente daquelas formuladas para as línguas européias. Estas últimas passaram por um longo período como escrita manuscrita, antes de serem impressas, momento no qual se desencadeou um debate ortográfico. Um exemplo dessa trajetória é o português, cujo debate ortográfico surge apenas com a impressão das primeiras gramáticas do século XVI, segundo Carvalhão Buescu (1982). Já entre as escritas em línguas ágrafas criadas no processo de evangelização, o debate sobre sua estandardização ocorre concomitante com a fase de sua formulação ortográfica. 


\title{
3. A Lingǘstica "a serviço de Igreja"1: seu uso como padrão de escrita para línguas ágrafas
}

\author{
"An íntimate relation existe between linguistic science and \\ Missionary labours" (Lepsius, 1863:1)
}

Desde o século XIX, a Lingüística ganhou um lugar cativo nas missões evangélicas como uma ciência aplicada à criação de escritas alfabéticas-tipográficas para línguas ágrafas. Dessa forma, as discussões a respeito dos critérios para uma escrita científica para transcrição das línguas foram utilizadas na construção de escritas missionárias.

Uma explicação para esta "relação íntima" entre Lingüística e missão pode ser encontrada na análise epistemológica que Roy Harris (1980) faz dessa disciplina. Segundo esse autor, a Lingüística constrói um modelo de análise da oralidade através de conceitos e categorias tomados da tradição alfabética-tipográfica. O dado lingüístico, seja fonológico, sintático, morfológico ou semântico, é construído dentro das regras normativas da escrita alfabética, como a de assinalar uma letra para cada som, a de dar importância à ordem linear no papel e a de manter o espaço em branco entre segmentos.

O sistema de escrita tipográfico repercutiu na formação da idéia do "tipo" lingüístico, que concebe a linguagem como uma forma fixa e constante. A idéia de invariança presente no conceito de tipo linguiístico está ausente, por exemplo, da escrita manuscrita, que contém a idéia de diversidade ao se apresentar com diferenças de caligrafia e com variações em relação ao destinatário (como nas cartas) e ao momento de escrever.

O uso da Lingüística como padrão de escrita alfabético-tipográfico pelas missões pode ser diferenciado em duas fases, segundo o tipo de conceito usado como base para definição de letra. A primeira fase corresponde ao emprego do alfabeto fonético como noção de letra (Lepsius, 1863) no século XIX. O lema ortográfico desse modelo foi "para cada som uma letra". A segunda fase se refere à constituição do nível fonológico; seu lema se transforma em "para cada fonema, uma letra" (Pike, 1938).

\subsection{Lepsius, $1863^{2}$ : para cada som, uma letra}

Um estilo de uso da Lingüística como padrão de escrita missionária no século XLX pode ser representado pelo IxvroStandardalphabetfor reducing unwritten languages

\footnotetext{
1 A expressão "Linguistics in the scrvice of the Church" foi utilizada por CHeason (1962) na sua aula inaugural de Lingüística num curso de formação de missionários.

2 A edição de Lepsius utilizada neste trabalho é a 2" revisada. Não houve acesso à primeira.
} 


\section{Cadernos de Linguagem e Sociedade, 2 (1) 1996}

andjòreign graphic systems to a uniform orthography in European letters, de C. R. Lepsius (1863), que emprega a fonética articulatória para elaborar um alfabeto.

Lepsius era um acadêmico especialista em temas sobre o Egito (arqueologia e decifração da escrita egípcia) e membro da Academia Real em Berlim. Fez uma tradução de Marcos para a língua Núbia, mas não era membro de missão.

A primeira parte do livro contém, além da explanação do seu sistema ortográfico, uma história das formulações de alfabetos standard. Na segunda parte, há propostas de ortografias para várias línguas do mundo, entre elas, um alfabeto para o Kiriri, elaborado com base em dados da gramática de Mamiani, traduzida para o alemão em 1852 (Lepsius, 1863: 299).

As discussões que redundaram na obra de Lepsius tiveram início em 1848, quando algumas missões inglesas envolvidas com uma política de evangelização pela tradução bíblica estabeleceram "regras para a redução de línguas ágrafas para a escrita alfabética com caracteres romanos" assinados pelo reverendo Henry Venn. A preocupação era evitar a variedade de notações ortográficas para uma mesma língua (Rutes, Lepsius, 1863: 40).

Uma segunda edição do livro Rules, em 1853, teve a assistência de acadêmicos (Lepsius, 1863: iii). A idéia era formular um alfabeto standard em bases científicas (Lepsius, 1863: iii). Os princípios científicos para construção de um alfabeto seriam a forma de garantir a uniformidade. O consenso científico se estabeleceu através da concepção de que o alfabeto deveria ser definido articulatoriamente ("fonologia" era o termo então usado para a explicação fisiológica dos sons). O tratamento articulatório dos sons acarretou mudanças na forma de apresentação do elenco de letras: elas não seriam mais ordenadas na ordem tradicional (abcd...) e sim agrupadas segundo suas afinidades "naturais" (guturais, dentais, labiais, etc) (Lepsius, 1863:41)

Para um alfabeto que surge com ambição de uniformidade (Lepsius, 1863:10), a introdução da fonética articulatória foi um elemento importante para a sua universalização, ou seja, para sua aplicação generalizada a todas as línguas do mundo.

Quanto à regra ortográfica adotada por Lepsius de atribuir uma letra para cada som, este lema tem origem no movimento de romanização, do qual participaram W. Jones, Volney, e Bopp, entre outros. Esse movimento tinha como objetivo a criação de ortografias latinas para línguas que possuíam sistemas de escrita não-latinos.

O lema ortográfico "para cada som uma letra" apontava para um tratamento dos sons como unidades "discretas", possíveis de serem expressas em letras. A "discretização" dos sons era um consenso. As divergências entre as propostas de alfabetos eram a respeito de quais eram os sons simples e os compostos, quais deveriam ser tratados por diacríticos ou dígrafo (grupo de letras). 
O objetivo do alfabeto de Lepsius era tanto acadêmico como missionário; o destino científico era sua utilização na lingüística comparativa, e o objetivo missionário era o seu uso em campanhas de alfabetização em línguas "nativas" (Lepsius, 1863: 23). Segundo o tipo de usuário do alfabeto, duas formas de seu emprego são mencionadas. No caso do seu uso por um europeu, seria necessário usar os sinais diacríticos. No caso dos "uncritical natives" (Lepsius, 1863: xii), estava contemplado seu uso simplificado. O objetivo era que fosse empregado pelo falante nativo sem a necessidade da presença do professor europeu (Lepsius, 1863: iv).

Adesões ao uso de um alfabeto standard tiveram mais êxito no mundo missionário do que no mundo acadêmico (Lepsius, 1863:40). Enquanto entre esses últimos, havia desavenças entre os seus proponentes, nas missões, o vínculo institucional dos seus membros obrigava a sua adoção. Havia recomendações para que os missionários consultassem a direção antes de imprimir qualquer material que contivesse algum desvio ao alfabeto padrão (Lepsius, 1863: 40).

As intenções a propósito do alfabeto de Lepsius eram de que se tornasse "universal" entre as missões (Lepsius, 1863: 1). Para tanto, a obra começa por uma série de apoios de várias missões, em especial The Church Missionary Society (Inglaterra), grupo que promoveu a discussão e elaboração desse alfabeto com a participação de acadêmicos.

Num período de cinco anos transcorrido entre a primeira e a segunda edição, o alfabeto de Lepsius foi utilizado em 14 línguas africanas e 6 asiáticas (Lepsius, 1863: xii). $\mathrm{O}$ alcance do emprego do alfabeto de Lepsius foi principalmente entre as línguas africanas, tendo uma menor incidência entre as línguas literárias asiáticas, onde a existência de sistemas de escritas tradicionais resistiu a sua substituição pelo alfabeto latino, não valendo ali argumentações fisiológicas para determinar um alfabeto.

\begin{abstract}
"Experience has convinced us that neither the internai consistency nor the physiological basis of our system of transcription has in the case of some of the sounds of these languages been sufficient to secure a ready acceptance for the symbols which we had proposed for their expression" (Lepsius, 1863: 7).
\end{abstract}

Entre as línguas indígenas do continente americano, a proposta ortográfica de Lepsius parece ter tido um uso inexpressivo.

\title{
3.2. Pike, 1938: para cada fonema, uma letra
}

Um segundo estilo missionário de uso da Lingüística para produção de escritas pode ser ilustrado pelo artigo Practical suggestions toward a common 


\section{Cadernos de Linguagem e Sociedade, 2 (1) 1996}

orthographyfor Indian languages of México for education ofthe natives within their own tongues, de Kenneth Pike (1938), membro da missão SMMMÉT Institute of Linguistics (SIL). Nesse artigo, a noção de fonema é tomada como equivalente para letra, assumindo a regra ortográfica "para cada fonema, uma letra". Esse modelo tornou-se a marca registrada dos projetos de alfabetização do SIL. Ele está presente, por exemplo, no manual de tradução bíblica de Eugene Nida (1947) (ex-membro do SIL) e num livro posterior de Pike, Phonemics: a techniquefor reducing languages to writing (1971).

A atenção em especial ao artigo de Pike, de 1938, é por ele ilustrar a aliança estabelecida entre missionários do SIL e indigenistas mexicanos na formulação de um modelo de educação pública para a população indígena que se caracterizou por iniciar a alfabetização na língua indígena. A escrita fonêmica proposta por Pike se inscreveu nesse programa de educação. Posteriormente, o projeto de alfabetização na língua indígena se difundiu na América Latina através da aliança do SIL com o movimento indigenista de cada país.

\subsubsection{México, década de 30: secularização da escrita missionária}

A aliança entre o SEL e indigenistas mexicanos se deu através àolnstituto Mexicano de Investigaciones Lingüísticas QMSL) e do Projeto Tarasco (1939-40), um programa de educação pública no México dirigido à população Purepecha, falantes de Tarasco. Os temas da aliança giraram em torno da Lingüística e da educação indígena.

O artigo de Kenneth Pike de 1938 foi publicado no periódico do Instituto Mexicano de Investigaciones Lingüísticas (IMIL) e foi dedicado à memória de Mariano Silva y Aceves, falecido um ano antes, como consta na epígrafe. O IMIL, criado por Mariano Silva Aceves em 1933, era um centro de pesquisa alinhado à proposta do indigenismo mexicano de defesa de uma escola para os grupos indígenas diferenciada da educação rural. A especificidade da escola indígena estaria no uso da língua indígena como veículo de propaganda dos ideais da revolução mexicana (Invest. Ling., 1933: 1: 9). Para o IMIL, Lingüística e indigenismo estavam conectados; seu interesse era tornar a Lingüística uma ciência aplicada à pedagogia na área indígena (Editorial em Invest. Ling., 1937: 3/4: 189-190).

Foi nesse clima intelectual favorável à Lingüística e às línguas indígenas entre os indigenistas que foi criado o SIL em 1936, por W.C. Townsend, seu presidente até a década de 1970. A missão estava alinhada à política de conversão centrada na tradução do Novo Testamento para as línguas ágrafas e na alfabetização da população indígena no domínio dessa escrita.

Por haver fortes restrições legais para atuar no país como missionários, o nome escolhido para a missão teve mais identidade acadêmica do que religiosa: 
Instituto de Linguísticaem tanto o nome do curso de verão organizado çelaLinguistic Society of America, como o nome da instituição criada por Mariano Silva Aceves. Townsend e seu grupo de tradutores missionários se tornaram publicamente lingüistas especializados no estudo das línguas indígenas .

"We will enter México as linguists rather than as missionaries.(...) The Indian languages must be learned and the New Testarnent translated into them. It matters not to us whether we be classified as missionaries or ditchdiggers if we be given a chance to labor toward that end (Townsend, in Hefley \& Hefley, 1974: 82).

A aliança entre o IMIL e o SIL foi possível pelo fato de ambos os grupos compartilharem do ponto de vista de que as línguas indígenas poderiam ser usadas como meio de proselitismo para seus projetos particulares (o de integração nacional ou o de conversão evangélica). A diferença era em relação a que textos pretendiam traduzir: discursos políticos e leis do governo ou o Novo Testamento.

Uma diferença latente entre os dois aliados foi em relação ao modo em que as línguas indígenas deveriam entrar na escola. No modelo educativo do IMIL não havia lugar para a iniciação da alfabetização na língua indígena, enquanto esta era essência do modelo missionário. A educação evangélica necessitava começar pela escrita na língua indígena para capacitar o índio a ler a tradução do Novo Testamento. A reivindicação do IMIL era apenas de que os professores das escolas indígenas fossem falantes das línguas das comunidades.

Essa diferença entre os dois parceiros pode ser observada nos artigos publicados no periódico do IMIL. Os artigos dos mexicanos a respeito de ortografia em línguas indígenas estavam voltados a responder questões a respeito de como a comunidade acadêmica deveria escrever os dados dessas línguas de forma regular e uniforme. Suas discussões sobre ortografia visavam basicamente o uso erudito, ou seja, o estabelecimento de um alfabeto para ser usado por pessoas que não falavam a língua, mas àomtnavam o espanhol, como no artigo "¥onetica àe\ Tarasco. Necesidad de adoptar una ortografia para los idiomas indígenas" (Ramirez, 1934, n. 2: 422).

Já os artigos do SIL visavam basicamente à produção de ortografias para serem usadas na educação dos grupos indígenas. Um exemplo é o artigo em foco deK.Pike(1938).

Em 1939, as propostas indigenistas de uma educação diferenciada para a população indígena acabaram sendo oficializadas no governo de Lázaro Cardenas através do Projeto Tarasco (1939-40). Além dos indigenistas mexicanos e do SIL, esse projeto de educação indígena contou com a participação de membros do Linguistic Society of America (Morris Swadesh e Norman McQuown). 
A principal mudança do Projeto Tarasco em relação ao que era a proposta do IMIL foi a iniciação da alfabetização na língua indígena e não em espanhol. A "mexicanização" do índio, ambicionada pelos indigenistas, não se fundamentaria mais na introdução do espanhol como forma de se alcançar a unificação nacional. A "língua nacional" entraria apenas no segundo e terceiro ano da escola, depois da alfabetização na língua indígena (Asambléa, 1940: xiii).

Através do Projeto Tarasco, a alfabetização nas línguas indígenas deixou de ser um modelo de escola da missão para ganhar o status de padrão de escola pública dirigida à população indígena. $\mathrm{O}$ que era antes um projeto de educação evangélico, ligado à política de conversão pela tradução bíblica, foi secularizado através da aliança com grupos intelectuais mexicanos. Numa publicação para evangélicos, W.C. Townsend menciona a conquista de um espaço na educação indígena oficial mexicana para o projeto evangélico.

"We carne to México at a time when the revolutionary movement was determined to do something for the forty or more Indian tribes in their own languages. The policy of trying to reach them exclusively in Spanish had been tried extensively and had not rendered the results which the Revolution demanded. Experienced leaders decided to change tactics, and now three important agencies have been formed with the purpose of studying the Indian languages and utilizing them in a great effort to bring the aborígenes out of ignorance, drunkenness, superstition, and poverty. Our prqject fitted into their scheme beautifully so that our problem now is not how to get in, but how to get sufficient volunteers to provide one or two for each tribe." (Townsend \& Griset, 1936)

Posteriormente, a alfabetização na língua indígena tornou-se modelo de educação pública de vários países na América Latina, contando sempre com a participação do SIL na sua montagem. O apoio para a difusão desse modelo de educação indígena em toda a América Latina veio através àolnstituto Indigenista Interamericano (ITI), fórum privilegiado utilizado pelo SIL para difundi-lo. Foi através do III, que o SIL implantou seu projeto de educação na Guatemala, Peru, Bolívia e Brasil.

\subsubsection{A naturalização da escrita fonêmica}

A regra ortográfica da proposta de alfabeto de Pike, em 1938, inclui o conceito de fonema como modelo para letra ("The ideal alphabet should have one 
letter, and one letter only for each phoneme, or the learning process will be retarded") (Pike, 1938: 87). Uma genealogia do conceito de fonema utilizado por ele tem como referência a tradição do Linguistic Society of America, em especial Sapir e Swadesh.

Pike adota uma definição de fonema como tendo uma realidade psicológica para o falante nativo. A concepção psicológica do fonema terá um importante papel na argumentação em defesa do programa de alfabetização na língua indígena. Essa definição do conceito sustentará um discurso a respeito da "naturalidade" do novo programa de educação. Por essa definição, a escrita de base fonológica ganhou um caráter "natural", quando empregada numa comunidade ágrafa, por ser considerada um retrato das estruturas mentais do falante nativo de uma determinada língua.

A naturalidade do alfabeto fonêmico na língua indígena serviu de crítica para os programas de alfabetização em espanhol das comunidades indígenas pelo fato de que os índios tinham determinados fonemas na sua língua materna, e se estava tentando alfabetizar com outros sons, que não os que eles, como falantes nativos, possuíam psicologicamente marcados.

A idéia de que cada língua tinha um conjunto limitado de sons, com valor intuitivo para os falantes nativos, levou a se considerar que uma escrita só poderia ser "natural", "eficiente", "perfecto", "sencillo" e "lógico" se reproduzisse esse nível psicológico da língua (Swadesh, 1940a/b/c). Um alfabeto deveria reconhecer esses sons e determinar para cada um deles um único símbolo.

Em suma, a argumentação tomada emprestada da Lingüística concebeu a alfabetização, no contexto indígena, como uma passagem sem diferenças culturais; desse ponto de vista, o índio não era tratado como membro de uma cultura ágrafa, mas como um "analfabeto".

\section{Conclusão}

A Lingüística, no contexto missionário, teve um destino diferente daquele definido por Bloomfield, que era o de vir a ser uma ciência comprometida com a oralidade. Entre os missionários, ela foi principalmente utilizada como um padrão de escrita alfabética-tipográfica para línguas ágrafas. A natureza letrada do conhecimento lingüístico acabou tornando essa ciência num modelo completo de escrita para línguas ágrafas, não apenas em relação à letra, mas em relação a outros conceitos e níveis. Esta postura de associar conceitos lingüísticos às questões gráficas está explicitada no livro de Eugene Nida dirigido a tradutores bíblicos missionários.

"In terms of the scientific analysis of the language, the alphabet represents the phonological system, the writing of word units 
concerns the morphological features of the language, and the punctuation entails an analysis of the syntactic structure" (Nida, 1947: 100).

Em comum, os dois modelos ortográficos aqui analisados tiveram o envolvimento de missionários e acadêmicos em sua formulação. A diferença entre eles aparece em relação ao grau de institucionalização da Lingüística no mundo missionário e à forma pela qual se difundiu o modelo evangélico de alfabetização nas línguas ágrafas.

Até a criação do SIL, a atuação como lingüista por parte dos missionários era uma questão de carreira individual e não uma exigência obrigatória da formação missionária. No caso do SIL em especial, a Lingüística veio a ocupar o papel central na seleção e capacitação dos seus membros. Esta missão vai abrir mão de que o tradutor bíblico missionário saiba grego, mas não a que domine a Lingüística (Pike,E., 1981:50).

Essa identidade institucional de lingüista por parte do membro do SIL foi determinada primeiramente pela situação política da América Latina que restringia a atuação dos missionários e depois pela política dessa missão de secularizar o modelo evangélico de alfabetização nas línguas indígenas. Nesse caso, a identidade científica favorecia a participação do membro do SIL nos programas oficiais de educação.

Quanto à difusão do modelo ortográfico como suporte de escritas missionárias, em Lepsius, esse modelo se limitava predominantemente às escolas das missões, diferentemente do SIL, onde a alfabetização em línguas ágrafas foi disseminada como modelo da escola pública para as populações indígenas.

Por fim, gostaria de relacionar a inserção da Lingüística nas missões: a) como um modelo exo-normativo de escrita; b)com o critério religioso de sentido literal,

Quanto ao primeiro aspecto, vou contrapor a tese da naturalidade da escrita fonológica a uma tese de caráter sociolinguístico, que definirá as escritas missionárias de base lingüística como externas em relação à comunidade ágrafa. Essa tese é retirada de J. Fishman (1988), num artigo no qual ele caracteriza a criação de um primeiro sistema de escrita numa comunidade ágrafa como estabelecida e orientada por regras externas à comunidade, devido a determinadas situações recorrentes, tais como:

i) a criação e a introdução dessas escritas são direta ou indiretamente feitas por pressões de grupos de fora da comunidade;

ii) a autoridade e regulação dessa escrita não é feita por parte do falante nativo, mas sim de grupos externos. Os padrões normativos dessa escrita estão dirigidos às necessidades do falante estrangeiro.

No caso dos programas de alfabetização nas línguas indígenas surgidos no bojo das escritas missionárias é possível encontrar essas situações: 
i) o aparecimento dessas escritas surge da estratégia de conversão pela tradução bíblica. São da iniciativa das missões.

ii) a autoridade e a regulação dessa escrita é feita pelo lingüista (missionário), um falante estrangeiro. É ele quem estabelece o processo de normatização ortográfica e que tem autoridade para corregir a escrita do falante nativo.

A questão da introdução da Lingüística como critério de sentido literal religioso surge a partir das considerações de D. Olson (1993) sobre o sistema de escrita alfabético-tipográfico como desambiguador e descontextualizador. O traço desambiguador desse sistema de escrita teria surgido com a distinção de vogais e consoantes na formação do alfabeto grego, o que manteve o léxico diferenciado graficamente, evitando ambigüidades presentes em possíveis homografias.

O critério de não-ambigüidade evocado por Olson está presente nas duas regras ortográficas propostas em Lepsius e Pike - "uma letra para cada som" e "uma letra para cada fonema".

$\mathrm{Na}$ formulação do alfabeto fonético internacional em 1888 (Jones, 1957), a regra "para cada som um letra" foi reelaborada como "para cada som distintivo uma letra". Essa nova versão da regra estipulava que se deveria distinguir os sons em letras diferentes, desde que esses sons correspondessem a mudanças no significado de uma palavra. A idéia de "sons distintivos" se contrapunha a uma escrita que sobrecarregasse nas minúcias da transcrição fonética, e que a tornasse não legível ("illisible").

Na formação do conceito de fonema, a idéia de "sons distintivos" se manteve através da metodologia de se procurar "pares mínimos". A diferença, porém, no caso da definição de fonema de Sapir, é que esse critério de sons distintivos ganhou um caráter psicológico. Esse critério, que respondia apenas as exigências de uma escrita desambiguadora, ganhou uma definição que lhe emprestava uma realidade psicológica (Swadesh, 1934: 118).

Os principais valores da escrita científica são máxima explicitude e nãoambiguidade, valores necessários ao lingüista, um falante não nativo que projeta sua escrita para os seus pares. Esses valores, presentes na discussão de uma escrita, abstraem de que os falantes nativos possuem algumas qualificações, como o comando da língua, e que, nesse contexto, os valores de não-ambigüidade e máxima explicitude não são tão importantes.

"A linguist, if he is an outsider, cannot rely on the native speaker's intuition that will make even inadequately spelled passages clear (...) Homographs are a problem for the outsider, but not for the native speaker" (Winter, 1983: 233). 
Em suma, em um projeto de tradução bíblica institucional - isto é gerenciada por missões - as características apontadas por Olson para o sistema alfabético-tipográfico teriam um caráter funcional, voltado para manter uma interpretação literalista do texto bíblico, como é o caso do SIL, onde literalidade é uma exigência institucional.

Algumas questões apontadas por Olson como próprias da tradição cultural da escrita alfabética-tipográfica são relevantes para pensar a escrita missionária:

i) o sistema alfabético permite, quando lido, um caráter restritivo em relação à variação lexical ou morfológica, se comparado aos sistemas ideográficos. Estes últimos não permitem a reprodução das mesmas palavras. Uma escrita fonológica determina, ao contrário, em larga medida as propriedades lexicais e morfológicas de uma leitura.

ii) o sistema tipográfico estabelece a figura do "tipo lingüístico", definido pelas características da repetição idêntica, sem variação semântica ou marcas particulares. Essa qualidade da escrita tipográfica terá importância na constituição de uma literalidade cristã. Dicionários, gramáticas, glossários, cartilhas e, finalmente, a Bíblia nas línguas indígenas são obras que institucionalizam, pela escrita, sinonímias para o discurso cristão, que deixam de ser móveis a cada situação, para serem fixadas.

Desse ponto de vista, o uso missionário da Lingüística pode ser interpretado como um reforço a um traço religioso, que é a exigência do literal como critério de fidelidade para a tradução bíblica.

\section{Referencias Bibliográficas}

American Bible Society. A guide for translators, revisers and editors working in connection with the American Bible Society. New York, apêndice de Nida, E. Bible translating, 1932 (1947).

Asamblea de Filologos y Lingüistas. Memória. México, Departamento Autônomo de Asuntos Indígenas, 1940.

Buescu, M. L. C. A gramaticalização das línguas exóticas no quadro cultural da Europa do século XVI. Revista de História Econômica e Social, 10:15-28,1982.

Clammer, J. R. Literacy and social change: a case stndy ofFiji. Leinder: E. J. Brill, $1976,218 \mathrm{pp}$.

Fishman, J. Ethnocultural issues in the creation, substitution, and revision of writing systems. In: Rafoth, B. \& Rubin, D. L. (eds.) The social construction ofwritten communication. New Jersey: Ablex Publishing, 1988, pp. 273-286.

Gleason, H. A. Linguistics in the service of the Church. Practical Anthropology, 9(5)205-219, 1962.

Gudschinsky, S. C. Handbookof literacy. SIL, Glendale, CA, 1951.

Harris, R. The language makers. London: Duckworth, 1980.

Hefley, J. \& Hefley, M. Uncle Cam: The story ofWilliam Cameron Townsend,founder 
ofthe Wycliffe Bible Translator and the Summer Institute of Linguistics. Waco: Word Books, 1974.

Investigaciones Linguisticas. México, Instituto Mexicano de Investigaciones Linguisticas, 1933-1938.

Jones, D. The history and meaning ofthe term "phoneme ". International Phonetics Association. Londres, 1957.

Lepsius C. R. Standard alphabetfor reducing unwritten languages andforeign graphic systems to a uniform orthography in European letters. 2nd ed. London: Williams \& Norgate, 1863.

Mauer, D. Tahiti de laparole a l 'écriture. Nouvelles Editions Latines. Paris: Dossier, 20, 30 pp., s.d.

Nida, E. Bible translating: an analysis of principies and procedures with special reference to aboriginal languages. American Bible Society. New York, 1947, $359 \mathrm{pp}$.

Olson, D. How writing represents speech. Language and Communication, 13(1)117,1993

Pike, E. Ken Pike, scholar and Christian. SIL. Dallas, 1981.268 pp.

Pike, K. Practical suggestions toward a common orthography for Indian languages of México for education ofthe natives within their own tongaes.Investigaciones Lingüísticas. Instituto Mexicano de Investigaciones Linguisticas, V (1-2) 8697, 1938.

Pike, K. Phonemics: a technique for reducing languages to writing. Ann Arbor: University of Michigan Press, 1971, 254 pp.

Ramirez, F. C. Fonética dei Tarasco: necesidad de adoptar una ortografia para los idiomas indígenas. Investigaciones Lingüísticas, 2: 422-427,1934.

Stoll, D. Pescadores de hombres o fundadores de império? Lima: DESÇO/ Centro de Estúdios y Promoción dei Desarrollo, 1985,489 pp.

Summer Iinstitute of Linguistics.Zifôraçy in the 90s: The role ofthe Summer Institute of Linguistics. 1990,25 pp.

Swadesh, M. The phonemic principie. Language, 10:117-129,1934.

Swadesh, M. El alfabeto y Ia labor de alfabetización. Primer Congreso Indigenista Interamericano. 1940a, pp. 271-274, mecanografado.

Swadesh, M. Métodos de Ia alfabetización en lenguas nativas. Primer Congreso Indigenista Interamericano. 1940b, pp. 275-280, mecanografado.

Swadesh, M. El Proyecto Tarasco: Ia ensenanza en lengua nativa. Primer Congreso Indigenista Interamericano. 1940c, pp. 281-286, mecanografado.

Townsend, W. C. \& Griset, E. Camp Wycliffe Chronicles, 1 (2) 1936.

Winter, W. Tradition and innovation in alphabet making. In: Coulmas, F. \& Ehlich, K. Writing infocus. Mouton Publishers, 1983, pp. 227-238. 